\title{
Anatomia caulinar de espécies epífitas de Cactaceae, subfamília Cactoideae
}

\author{
Greta Aline Dettke ${ }^{1,3}$ e Maria Auxiliadora Milaneze-Gutierre ${ }^{2}$
}

Recebido: 27.03.2008; aceito: 30.10.2008

ABSTRACT - (Stem anatomy of epiphytic Cactaceae, subfamily Cactoideae). This study aimed at characterizing the stem of seven epiphytes species of Cactaceae: Epiphyllum phyllanthus, Hatiora salicornioides, Lepismium cruciforme, $L$. warmingianum, Rhipsalis baccifera, $R$. cereuscula and $R$. sulcata, from a fragment of Seasonal Semidecidual Forest in Maringá, northwest of the State of Paraná. Most species had stems covered by thick cuticle sometimes with an adjacent epicuticular layer. They showed parallelocytic stomata, frequently sunken in the epidermis. Underlying, they are 1-3 layers of collenchymatous hypoderm and a great proportion of cortical parenchyma, presenting mucilaginous and crystalliferous cells. The central cylinder has the vascular bundles forming a concentric ring, always with cap of fibers in the phloem pole, and the pith can be or not sclerified. Starch and lipid substances are the main storage compounds of these plants.

Key words: Epiphyllum, Hatiora, Lepismium, Rhipsalis

RESUMO - (Anatomia caulinar de espécies epífitas de Cactaceae, subfamília Cactoideae). Este estudo teve o objetivo de caracterizar anatomicamente o caule de sete espécies epífitas da família Cactaceae: Epiphyllum phyllanthus, Hatiora salicornioides, Lepismium cruciforme, L. warmingianum, Rhipsalis baccifera, $R$. cereuscula e $R$. sulcata, ocorrentes em um fragmento de Floresta Estacional Semidecidual do município de Maringá, noroeste do Paraná. A maioria apresentou caule recoberto por cutícula espessa, por vezes com uma camada epicuticular adjacente. Os estômatos são do tipo paralelocítico, freqüentemente localizados em depressões da epiderme. Subjacentes, estão de 1 a 3 estratos de hipoderme colenquimática e uma grande proporção de tecido cortical, contendo células mucilaginosas e idioblastos cristalíferos. O cilindro central tem os feixes vasculares orientados concentricamente, sempre com calota de fibras no pólo floemático, encerrando uma medula que pode ser ou não lignificada. Grãos de amido e substâncias lipídicas são as principais reservas destas plantas.

Palavras-chave: Epiphyllum, Hatiora, Lepismium, Rhipsalis

\section{Introdução}

A família Cactaceae possui distribuição neotropical, incluindo cerca de 1500 espécies, das quais, cerca de $10 \%$ são representadas por plantas epífitas, de acordo com Benzing (1990). Estas, em sua grande maioria, estão distribuídas em duas tribos: Hylocereeae, com os principais gêneros Epiphyllum, Hylocereus e Selenicereus; e Rhipsalideae, com os gêneros Hatiora, Lepismium, Rhipsalis e Schlumbergera (Barthlott \& Hunt 1993, Nyffeler 2002).

Os estudos anatômicos em Cactaceae se iniciaram por volta do século dezesseis e buscavam, principalmente, relações anatômicas com as diferentes formas e o metabolismo fotossintético dos caules destas espécies. Estudos mais recentes, dentre eles os de Nyffeler \& Eggli (1997), Mauseth \& PlemonsRodriguez (1998), Terrazas \& Arias (2003), Soffiatti \& Angyalossy (2007) e Calvente et al. (2008), utilizam caracteres anatômicos na sistemática da família, e demonstram a importância da inclusão dos caracteres anatômicos na análise filogenética do grupo.

As características anatômicas, morfológicas e fisiológicas de espécies de Cactaceae constituem adaptações aos ambientes áridos e semi-áridos (Gibson \& Nobel 1986). Dentre as modificações fisiológicas registra-se a rápida absorção de água pelas raízes depois de uma seca prolongada e o metabolismo ácido das crassuláceas (CAM), enquanto que a presença de costelas, espinhos, tricomas e ausência de folhas, resultando em um caule fotossinteticamente ativo,

1. Programa de Pós-Graduação em Botânica, Universidade Federal do Rio Grande do Sul, Av. Bento Gonçalves 9500, Bloco IV, Prédio 43433, Campus do Vale, Bairro Agronomia, 91501-970 Porto Alegre, RS, Brasil

2. Universidade Estadual de Maringá, Departamento de Biologia, Avenida Colombo 5790, Jardim Universitário, 87020-970 Maringá, PR, Brasil

3. Autor para correspondência: gretadet@yahoo.com.br 
são algumas das principais adaptações morfológicas encontradas neste grupo (Nobel 1978, Scheinvar 1985, Darling 1989). Dentre as modificações anatômicas caulinares mais expressivas, Terrazas \& Mauseth (2002) destacam a presença de cera epicuticular, cutícula espessa, estômatos localizados em depressões da epiderme (em algumas espécies), hipoderme colenquimática e o desenvolvimento de grandes proporções de tecido parenquimático com células mucilaginosas.

Tendo em vista a importância da realização de estudos anatômicos em representantes de Cactaceae, este estudo teve o objetivo de caracterizar anatomicamente o caule de sete espécies epífitas da família, ocorrentes no município de Maringá, Paraná (Brasil), em busca de caracteres vegetativos que possam auxiliar na identificação destas espécies.

\section{Material e métodos}

No presente estudo, foram analisadas as seguintes espécies epífitas: Epiphyllum phyllanthus (L.) Haw., Hatiora salicornioides f. bambusoides (Weber) Supplie, Lepismium cruciforme (Vell.) Miq., L. warmingianum (K. Schum.) Barthlott, Rhipsalis baccifera (J.S. Muell.) Stearn, $R$. cereuscula Haw. e R. sulcata F.A.C. Weber, provenientes de um fragmento de Floresta Estacional Semidecidual (APP "Parque do Ingá") localizada no município de Maringá, noroeste do Paraná, com exceção de $H$. salicornioides, coletado em outros fragmentos vegetais do mesmo município.

As exsicatas das espécies estudadas encontramse depositadas no Herbário da Universidade Estadual de Maringá (HUEM), sob registros: Epiphyllum phyllanthus - BRASIL, PARANÁ: Maringá, Parque do Ingá, 23-I-2006, G.A. Dettke 27 (HUEM); Hatiora salicornioides f. bambusoides - BRASIL, PARANÁ: Maringá, Parque Ecológico da UEM, 16-VIII-2005, G.A. Dettke 47 (HUEM); Lepismium cruciforme - BRASIL, Paraná: Maringá, Parque do Ingá, 21-IX-2005, G.A. Dettke 19 (HUEM); Lepismium warmingianum - BRASIL, PARANÁ: Maringá, Parque do Ingá, 21-IX-2005, G.A. Dettke 21 (HUEM); Rhipsalis baccifera - BRASIL, PARANÁ: Maringá, Parque do Ingá, 26-I-2006, G.A. Dettke 43 (HUEM); Rhipsalis cereuscula - BRASIL, PARANÁ: Maringá, Parque do Ingá, 21-IX-2005, G.A. Dettke 20 (HUEM); Rhipsalis sulcata - BRASIL, PARANÁ: Maringá, Parque do Ingá, 17-II-2005, G.A. Dettke 11 (HUEM).

Para a análise histológica foram preparadas seções anatômicas, à mão livre, com auxílio de lâmina de barbear, de fragmentos frescos de caules jovens e maduros (pós-floração) de, no mínimo, cinco indivíduos de cada população. As seções foram clarificadas em hipoclorito de sódio $33 \%$ e coradas com azul de astra e safranina (soluções aquosas a 1\%, na proporção 9:1 v/v) (Bukatsch 1972, modificado por Kraus \& Arduin 1997) e finalmente montadas em gelatina glicerinada, como lâminas semi-permanentes.

Para os testes microquímicos utilizou-se vermelho de rutênio para a detecção de compostos pécticos (Johansen 1940), lugol para os grãos de amido (Sass 1951), cloral hidratado (60\%) em solução com ácido sulfúrico $25 \%$ em etanol absoluto, para revelar a presença de oxalato de cálcio, e sudan IV para a identificação de cutina e demais substâncias lipídicas (Gerlach 1984). As amostras foram manipuladas poucas horas após a coleta, sempre no período matutino.

Os diagramas caulinares foram elaborados com o auxílio de câmara clara e as demais ilustrações obtidas com câmera digital acoplada ao fotomicroscópio Olympus (modelo BX51) e programa "Image Pro Express", projetando-se, nas mesmas condições ópticas, as escalas correspondentes.

\section{Resultados e Discussão}

Os principais caracteres anatômicos das espécies estudadas encontram-se na tabela 1, e os diagramas das seções transversais dos caules nas figuras 1-10.

Epiphyllum phyllanthus tem caule dorsiventral (ou achatado) em seção transversal (figura 1), raramente apresentando uma costela supranumerária. Em Lepismium cruciforme e L. warmingianum este órgão se apresenta predominantemente no formato tricostelado ou dorsiventral (figuras 2-6). Hatiora salicornioides, Rhipsalis baccifera, $R$. cereuscula e $R$. sulcata apresentam caules cilíndricos (figuras 7-10).

Nos caules das espécies analisadas, a epiderme apresenta-se uniestratificada, lisa ou papilosa (figuras 11-17). Cutícula lisa está presente na maioria das espécies analisadas, com exceção de H. salicornioides, $L$. cruciforme e $R$. baccifera. Em $H$. salicornioides, as células epidérmicas, juntamente com a cutícula, formam papilas, dando ao caule um aspecto ou estriado (figura 12). Em L. cruciforme e R. baccifera, a epiderme é interrompida por depressões ou sulcos (figura 15), menos expressivas em seção transversal em L. cruciforme (figura 13). Estes sulcos são regulares, dispostos paralelamente em $R$. baccifera (figura 18), e irregulares em L. cruciforme (figura 19). 
Tabela 1. Características anatômicas de sete espécies epífitas de Cactaceae. 01=Epiphyllum phyllanthus, 02=Lepismium cruciforme, 03=L. warmingianum, 04=Hatiora salicornioides, 05=Rhipsalis baccifera, 06=R. cereuscula e 07=R. sulcata . (x) indica presença da característica avaliada.

\section{Característica /planta \\ Cutícula* (espessura em $\mu m$ )}

Fina

Moderadamente espessa

$$
\text { Espessa }
$$

Cera epicuticular

Epiderme

Lisa
Papilosa

Estômatos em depressões

Orientação dos poros estomáticos em relação ao eixo axial da planta

\section{Aleatória}

Paralelo

Perpendicular

Hipoderme espessada

Hipoderme (estratos celulares)

Córtex (estratos celulares)

Cavidades mucilaginosas

Medula esclerificada

Posição dos feixes corticais
Aleatória
Radiada (raios)

X

X

Amilífera

Lipídica

Inclusões celulares

Cristais aciculares

Cristais amorfos

Cristais prismáticos

Drusas
01

02

03

04

05

06

07

\section{$2-3$}

10-14

$15-23$

X

X com sulcos
irregulares

X

$\begin{array}{ccccccc} & \mathrm{X} & \mathrm{X} & & & & \\ & & & \mathrm{X} & \mathrm{X} & \mathrm{X} & \mathrm{X} \\ \text { pouco } & \mathrm{X} & \mathrm{X} & \mathrm{X} & \mathrm{X} & \mathrm{X} & \mathrm{X} \\ 1 & 1 & 1 & 1 & 1-2 & 1-2 & 2-3 \\ 7-18 & 8-22 & 11-30 & 10-14 & 12-15 & 9-11 & 15-19 \\ \mathrm{X} & \mathrm{X} & & \mathrm{X} & & \mathrm{X} & \mathrm{X} \\ & \mathrm{X} & \mathrm{X} & & & & \mathrm{X}\end{array}$

X X X

X $\begin{array}{cc}\text { sem } & \text { com sulcos } \\ \text { sulcos } & \text { paralelos }\end{array}$

14-16

15-20

X

X 


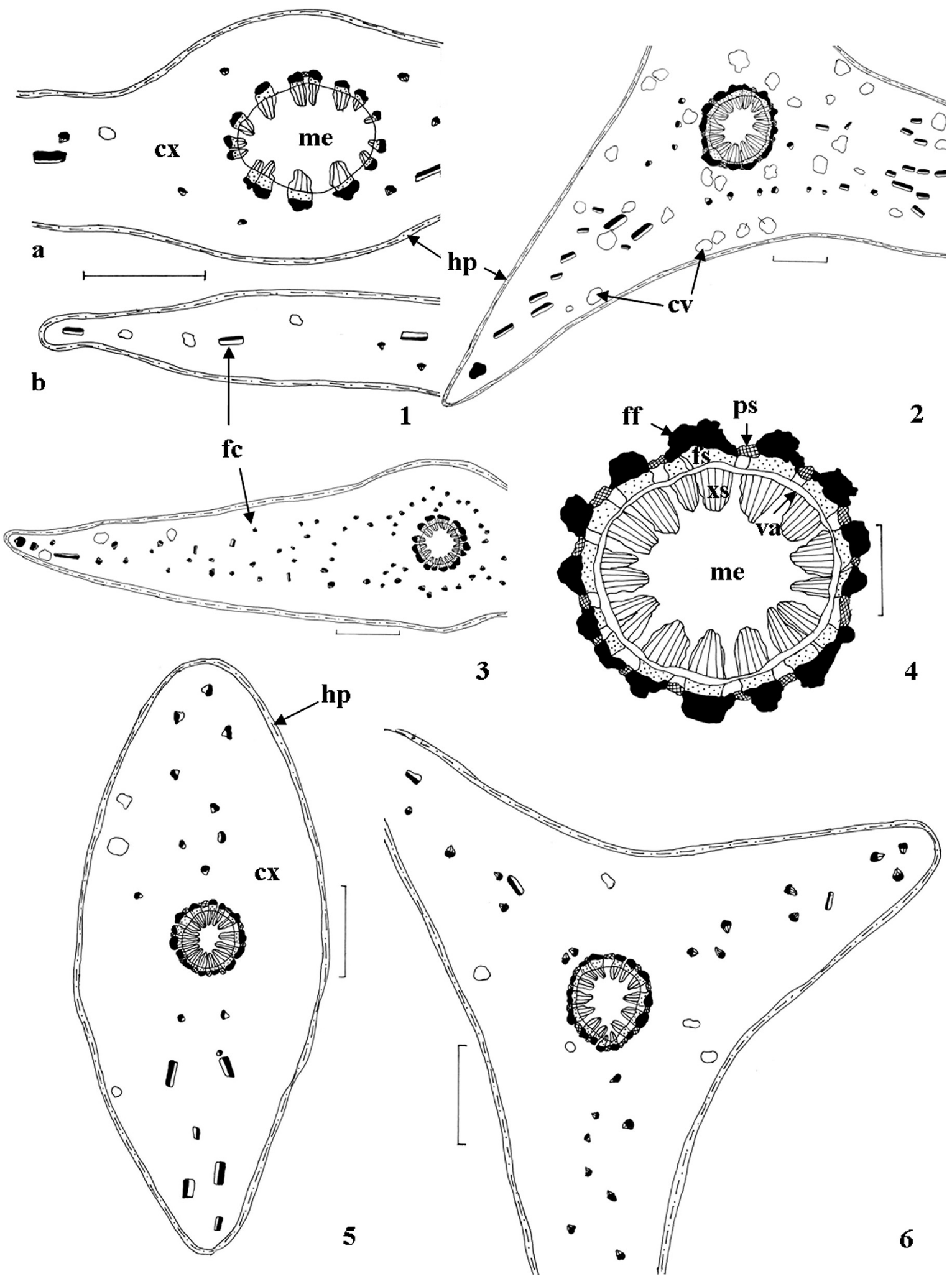

Figuras 1-6. Representação esquemática das seções transversais dos caules. 1. Epiphyllum phyllanthus, região central (a) e borda (b). 2-4. Lepismium cruciforme 2. Formato tricostelado. 3. formato achatado. 4. detalhe do cilindro central). 5-6. L. warmingianum. 5. Formato achatado. 6. Formato tricostelado. $\mathrm{cv}=$ cavidade mucilaginosa; $\mathrm{cx}=$ córtex; $\mathrm{fc}=$ feixe cortical; $\mathrm{ff}=$ calota de fibras associada ao floema; $\mathrm{fs}$ = floema secundário; $\mathrm{hp}=$ hipoderme colenquimática; me = medula; $\mathrm{ps}=$ periciclo esclerificado; va = câmbio vascular; $\mathrm{xs}=$ xilema secundário. Barras de escala: $1 \mathrm{~mm}(1-3,5-6)$ e $100 \mu \mathrm{m}(4)$. 

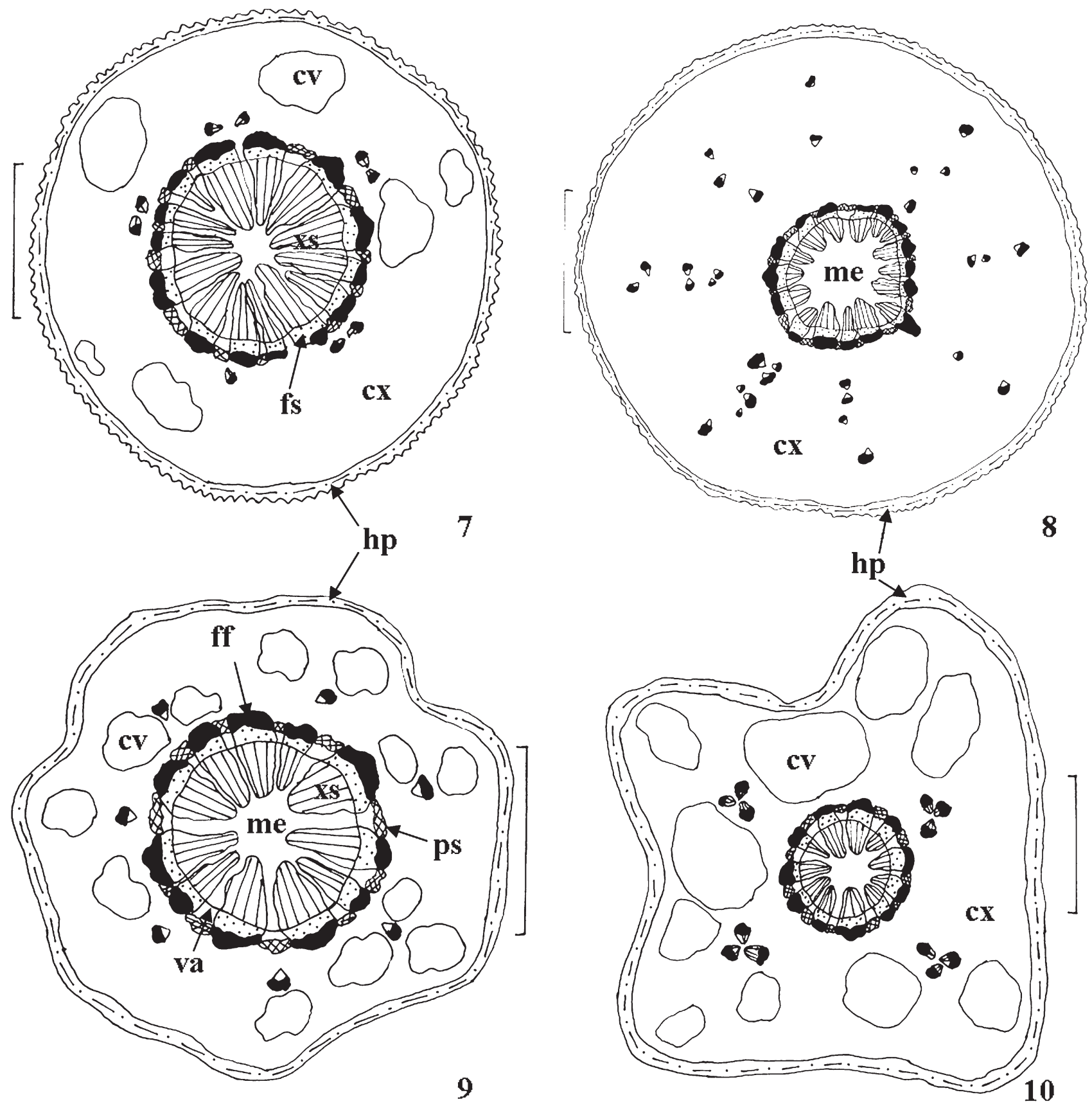

Figuras 7-10. Representação esquemática das seções transversais dos caules. 7. Hatiora salicornioides. 8. Rhipsalis baccifera. 9. R. cereuscula. $10 . R$. sulcata. $\mathrm{cv}=$ cavidade mucilaginosa; $\mathrm{cx}=$ córtex; $\mathrm{ff}=$ calota de fibras associada ao floema; fs = floema secundário; hp = hipoderme colenquimática; me = medula; ps = periciclo esclerificado; va = câmbio vascular; xs = xilema secundário. Barras de escala $=1 \mathrm{~mm}$. 
A epiderme encontra-se impermeabilizada por cutícula espessa, entre 10 e $23 \mu \mathrm{m}$, em $L$. warmingianum, $H$. salicornioides, $R$. cereuscula e $R$. sulcata. $R$. baccifera apresentou cutícula moderadamente espessa (7-9 $\mu \mathrm{m})$ e E. phyllanthus e L. cruciforme apresentaram-na fina, com espessuras entre 2 e $3 \mu \mathrm{m}$ (tabela 1). As categorias acima estão de acordo com Morris et al. (1996), ao estudarem espécies de Orchidaceae da subtribo Dendrobiinae, sendo finas $(<3 \mu \mathrm{m})$, moderadamente espessas (3-10 $\mu \mathrm{m})$ ou espessas $(>10 \mu \mathrm{m})$. Em L. warmingianum forma-se uma camada evidente de cera epicuticular, com espessura entre 8 e $18 \mu \mathrm{m}$ (figura 14), facilmente destacável quando a planta está desidratada, e de coloração esbranquiçada, referida por Metcalfe \& Chalk (1979) como freqüente para a família Cactaceae, porém não evidenciada, em microscopia óptica, nas outras espécies deste estudo.

A espessura da cutícula, segundo Terrazas \& Arias (2003), pode variar entre 1 e $25 \mu \mathrm{m}$, porém os autores recomendam especial atenção quanto ao uso da espessura em análises taxonômicas, devido à variabilidade que pode ocorrer frente às diversas condições ambientais onde os indivíduos se desenvolvem. A presença de uma cutícula espessa e fortemente cutinizada atua como uma capa impermeável e impede a perda de água do corpo da planta por transpiração (Gibson \& Nobel 1986), tendo especial importância para espécies epífitas, onde este recurso é limitado, conforme observaram Helbsing et al. (2000). Em adição, as ceras epicuticulares, devido à sua composição química e à possibilidade de constituirem uma película na superfície da cutícula, atuam como interfase entre a célula vegetal e o meio, destacando-se como principal barreira protetora contra a perda de água por transpiração excessiva, ação de patógenos, radiação solar e entrada de produtos químicos e contaminantes nos tecidos vegetais (Domínguez et al.1998), constituindo assim, uma característica singular para a sobrevivência dos indivíduos na condição epifítica.

As características das camadas superficiais dos caules das Cactaceae se revelam de grande importância para a distinção de gêneros e espécies, como comprovaram Terrazas \& Arias (2003) para Cactoideae e Calvente et al. (2008) para espécies de Rhipsalis. A presença de epiderme com parede periclinal externa lisa é característica predominante nas espécies de Cactaceae, conforme salientado por Gibson \& Nobel (1986), Nyffeler \& Eggli (1997), Terrazas \& Arias (2003) e Soffiatti \& Angyalossy
(2007). No entanto, algumas espécies apresentam a superfície epidérmica com aspecto ondulado ou estriado, devido à presença de papilas, conforme verificado por Nyffeler \& Eggli (1997) para várias espécies de Eriosyce (Notocacteae), semelhantes às encontradas em $H$. salicornioides neste estudo. Outro fator que dá à epiderme o aspecto ondulado é a organização regular ou irregular das células epidérmicas, delimitadas por sulcos, nos quais a cutícula se projeta internamente, como observado em $L$. cruciforme e $R$. baccifera e também relatado por Calvente et al. (2008) em espécies epífitas de Rhipsalis.

Os complexos estomáticos de algumas espécies analisadas encontram-se representados nas figuras 18-23. Todas apresentaram estômatos do tipo paralelocítico, com as células epidérmicas comuns dispostas radialmente em torno das células subsidiárias. Os estômatos estão localizados em depressões da epiderme nas espécies de Rhipsalis analisadas, como ilustrado em $R$. baccifera e $R$. cereuscula (figuras 15, 23). Este fato dificulta a observação de todas as células subsidiárias em vista superficial ao microscópio óptico, dando a impressão de tratar-se de estômatos do tipo paracítico.

Estômatos do tipo paralelocítico são característicos da subfamília Cactoideae, conforme as descrições de Eggli (1984) e Terrazas \& Arias (2003), a qual também pertencem as espécies sob análise. Neste tipo de estômato, há dois pares de células subsidiárias paralelas às células guarda, em vez de um par, como no tipo paracítico. A ocorrência de estômatos localizados em depressões da epiderme, de acordo com LozaCornejo \& Terrazas (2003), é bastante freqüente em cactos, podendo ser interpretada como uma adaptação para reduzir a transpiração, pois implica na formação de uma câmara supra-estomática.

Como indicado na tabela 1 , os poros estomáticos podem estar orientados em sentido paralelo, perpendicular ou aleatório em relação ao eixo axial da planta, dependendo da espécie. Metcalfe \& Chalk (1979) chamam a atenção para a orientação dos poros estomáticos nas Cactaceae e seu possível valor taxonômico, tendo citado o gênero Rhipsalis com estômatos orientados transversalmente ou paralelamente ao eixo axial, e Epiphyllum com orientação paralela ou aleatória, como também verificado nas espécies destes gêneros sob análise. Os resultados apresentados na tabela 1 também estão de acordo com Eggli (1984) para E. phyllanthus, $H$. salicornioides e $R$. baccifera, quanto a este aspecto. 

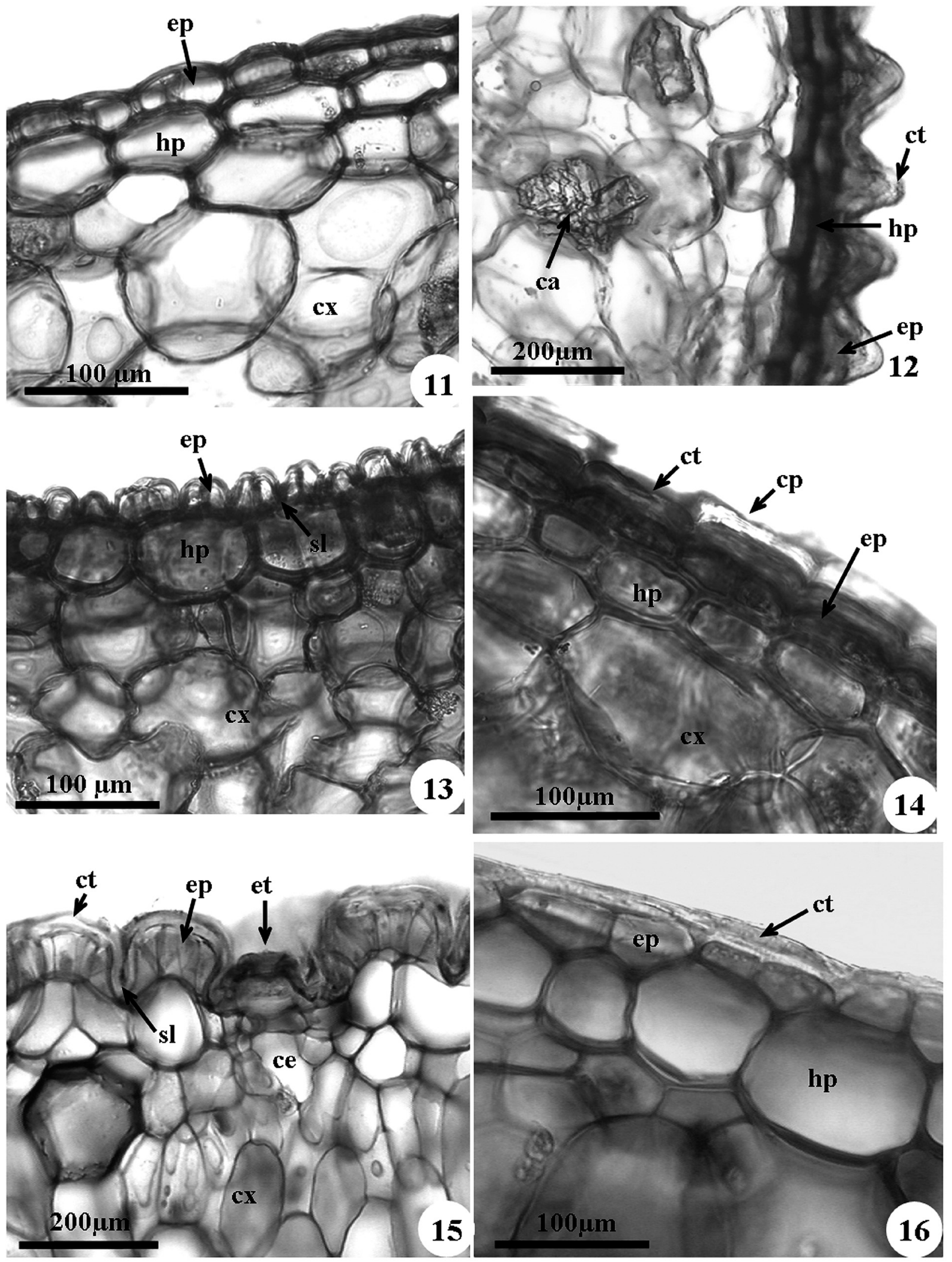

Figuras 11-16. Seções transversais da região superficial do caule. 11. Epiphyllum phyllanthus. 12. Hatiora salicornioides. 13. Lepismium cruciforme. 14. L. warmingianum 15. Rhipsalis baccifera. 16 . . cereuscula $. \mathrm{ca}=$ cristal amorfo; $\mathrm{ce}=$ câmara subestomática; $\mathrm{cp}=\mathrm{cera}$ epicuticular; ct = cutícula; $\mathrm{cx}=$ córtex; $\mathrm{ep}=$ epiderme; et = estômato; $\mathrm{hp}=$ hipoderme; $\mathrm{sl}$ = sulco da cutícula. 


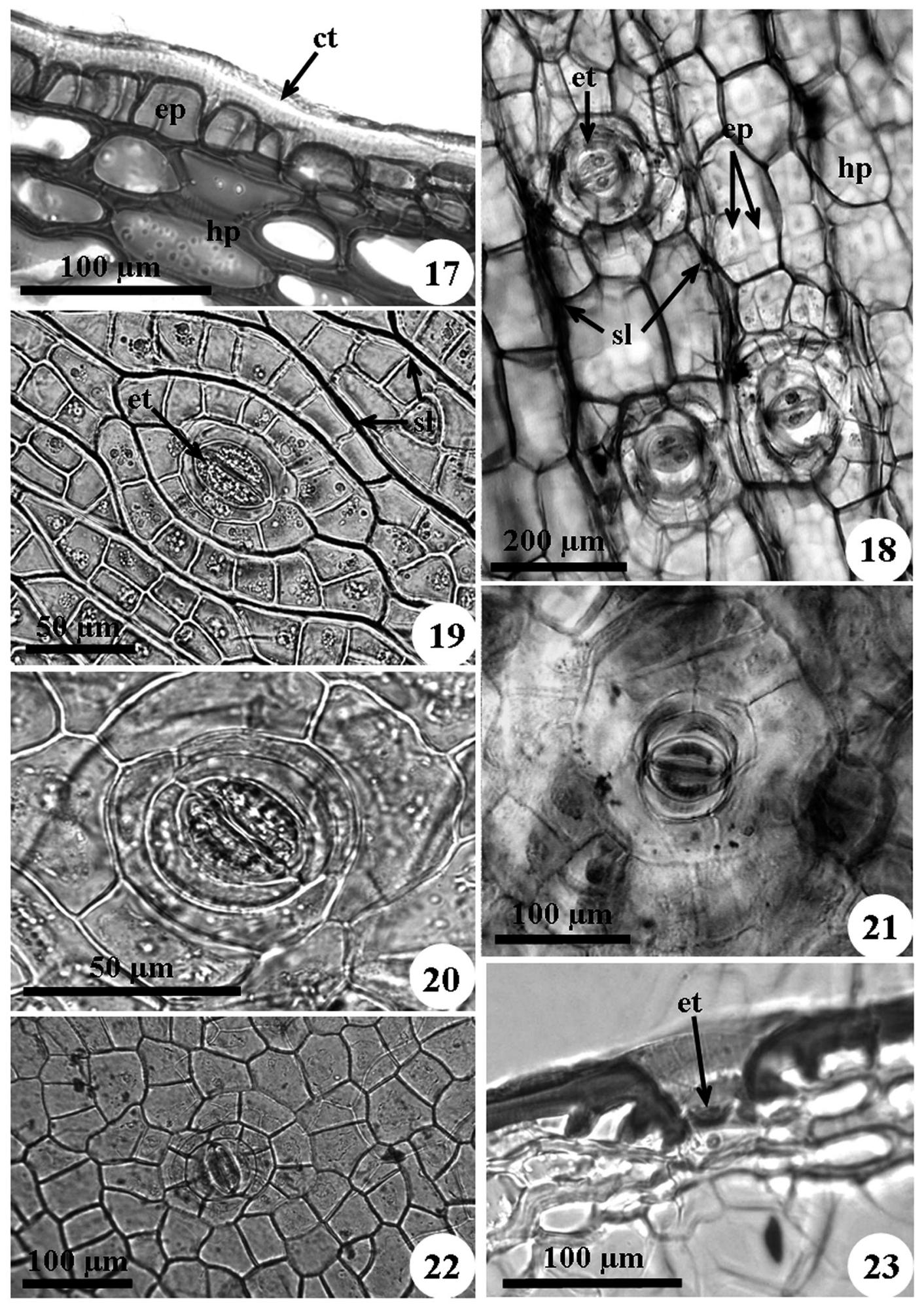

Figuras 17-23. Seções transversais e paradérmicas do caule. 17. Seção transversal da região superficial do caule de Rhipsalis sulcata. 18. Seção paradérmica invertida em $R$. baccifera, onde são observadas as células da hipoderme em primeiro plano (hp) e as células epidérmicas em segundo plano (ep). 19-22. Seções paradérmicas, mostrando os complexos estomáticos. 19. Lepismium cruciforme. 20. Epiphyllum phyllanthus. 21. Hatiora salicornioides. 22. Rhipsalis cereuscula. 23. Seção transversal de um estômato de $R$. sulcata. ct = cutícula; ep = epiderme; et = estômato; $\mathrm{hp}=$ hipoderme; $\mathrm{sl}=$ sulco da cutícula. 

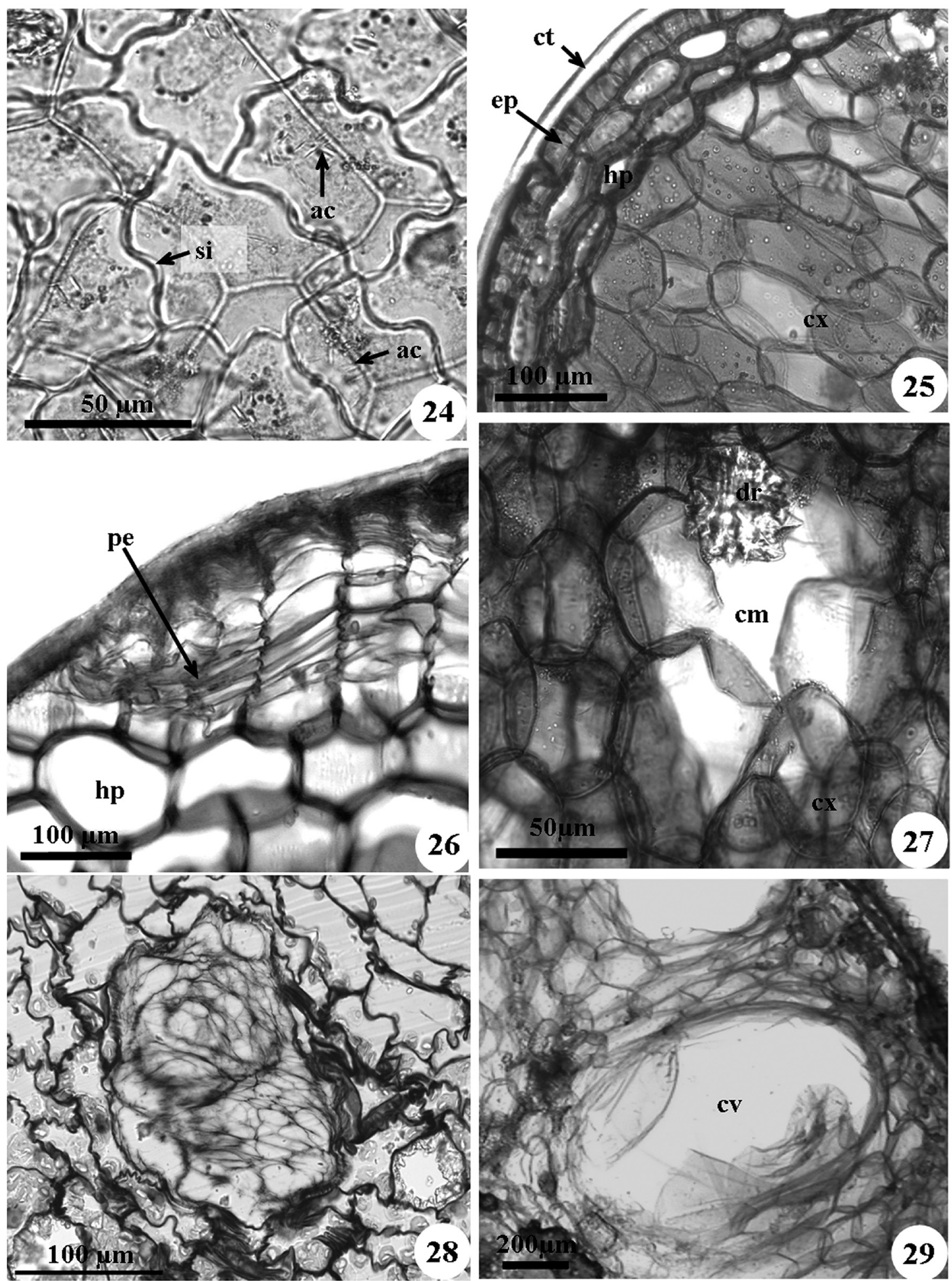

Figuras 24-29. Seções paradérmica e transversais do caule. 24. Seção paradérmica do caule de Epiphyllum phyllanthus. 25-26. Seções transversais da região superficial do caule. 25. Rhipsalis sulcata. 26. R. cereuscula. 27. Região cortical do caule de Lepismium warmingianum. 28. Região cortical do caule de R. cereuscula, mostrando célula mucilaginosa. 29. Região superficial do caule de Hatiora salicornioides. $\mathrm{ac}=$ cristais aciculares da epiderme; $\mathrm{cm}=$ célula mucilaginosa; $\mathrm{ct}=$ cutícula; $\mathrm{cv}=$ cavidade mucilaginosa; $\mathrm{cx}=\mathrm{có}$ rtex; $\mathrm{dr}=$ drusas; $\mathrm{ep}=$ epiderme; $\mathrm{hp}=$ hipoderme; $\mathrm{pe}$ = início de formação de periderme por divisão das células epidérmicas; si = sinuosidade das paredes anticlinais da epiderme. 
As demais células epidérmicas, em vista frontal, apresentam-se quadrangulares ou poliédricas na maioria das espécies, e com paredes anticlinais levemente sinuosas em E. phyllanthus (figuras 20, 24). A presença de epiderme unisseriada é caráter comum para a família, sendo a do tipo múltipla rara, como relatado por Loza-Cornejo \& Terrazas (2003) em espécies de cactos não-epífitos.

Nos estágios caulinares juvenis, subjacente à epiderme, observa-se uma hipoderme colenquimática composta por uma a três camadas contínuas (tabela 1), pouco perceptíveis por seu leve espessamento parietal, distinguíveis apenas pela ausência de cloroplastídeos e cujas células são de formato alongado anticlinalmente, diferindo das demais células corticais. Em porções caulinares mais diferenciadas, tal hipoderme adquire espessamento típico do tecido colenquimático do tipo anelar (figuras 12-17, 25), com exceção de E. phyllanthus, que permanece sem espessamento pronunciado (figura 11). Segundo Mauseth (1988), as paredes das células da hipoderme colenquimática contêm altas concentrações de pectina e hemicelulose, contribuindo com a função de suporte para a planta e possível barreira para patógenos. Quanto a este caráter, Metcalfe \& Chalk (1979) relatam hipoderme pouco desenvolvida apenas para o gênero Epiphyllum, tal como no presente estudo.

Tanto as células da epiderme quanto da hipoderme, de diversas espécies de Cactaceae, podem apresentar drusas, cristais amorfos de sílica ou oxalato de cálcio (Terrazas \& Mauseth 2002, Loza-Cornejo \& Terrazas 2003, Terrazas \& Arias 2003), não sendo encontrados nas espécies sob análise. Cristais aciculares, segundo os autores acima, são incomuns na família Cactaceae, tendo Loza-Cornejo \& Terrazas (2003) e Dettke et al. (2004) os encontrado somente nas células epidérmicas de várias espécies de Epiphyllum e Selenicereus (Cryptocereus), sendo, neste estudo, visualizadas em abundância em E. phyllanthus (figura 24).

Em porções mais velhas do caule, de todas as espécies em estudo, desenvolve-se uma periderme por divisões das células epidérmicas (figura 26); a hipoderme pode permanecer, ou então, em estados mais avançados, as células externas do córtex podem desempenhar esta função e a hipoderme é destacada, como também relatado por Terrazas \& Arias (2003) e Metcalfe \& Chalk (1979).

O parênquima cortical apresenta-se formado por 7 a 30 estratos celulares, dependendo da espécie (tabela 1) e do formato do caule (figuras 1-10). Suas células, tipicamente de parênquima aquífero, possuem paredes finas, tamanhos variados e formato aproximadamente isodiamétrico, geralmente menores nas camadas mais externas. Por todo o córtex estão dispersos, aleatoriamente, idioblastos de mucilagem de formato esférico a ovalado, que podem alcançar grandes dimensões (de 2 a 4 células normais), conforme observado na figura 28 , sendo também observado por Mauseth (1995); ou sofrem lise, ocasionando a formação de cavidades (figura 29), como observadas em L. cruciforme, $H$. salicornioides, $R$. cereuscula e $R$. sulcata.

Mauseth (1995) distingue duas regiões nos caules de Cactaceae: uma mais externa, formada por clorênquima em paliçada, e uma interna, com células aquífferas freqüentemente colapsadas (eventualmente com cavidades mucilaginosas), que estão relacionadas com o metabolismo da planta, estocagem e movimento de água. $\mathrm{O}$ clorênquima em paliçada não foi observado neste estudo.

No tecido cortical também estão presentes idioblastos contendo drusas de várias dimensões, cristais prismáticos, cristais amorfos ou pequenos cristais aciculares, dependendo da espécie (tabela 1), mais abundantes em tecidos maduros, todos de oxalato de cálcio e com disposição aleatória (figuras 27, 30), além de numerosas gotículas lipídicas em $L$. cruciforme, $L$. warmingianum e $R$. sulcata (tabela 1).

Idioblastos com drusas e outros cristais, em células corticais, são comuns na família, estando geralmente agrupados (Metcalfe \& Chalk 1979) ou, quando as células mucilaginosas são ausentes ou raras, possuem grande variação de número e tamanho, dependendo do ambiente (Terrazas \& Arias 2003). É relatada a função dos cristais de oxalato de cálcio como proteção contra a herbivoria, pelo fato de causarem irritações em vertebrados quando ingeridos e ao controle dos níveis de cálcio citossólico (Franceschi \& Horner 1980, Paiva \& Machado 2005).

Reserva amilífera foi encontrada na maioria das espécies, com exceção de $R$. cereuscula (tabela 1). Os grãos de amido estão frequentemente localizados nas células dos raios e da medula, sendo menos freqüente nas células corticais.

Ainda no córtex estão presentes os feixes corticais, caracteristicamente com uma calota de fibras no pólo floemático (figuras 31, 32). Estão orientados em várias direções nas amostras analisadas de $E$. phyllanthus, L. cruciforme e L. warmingianum (figuras 1-5). Nas demais espécies analisadas, estes feixes são em menor número, geralmente constante, localizados perifericamente ao cilindro central e com orientação axial (figuras 6-10). 


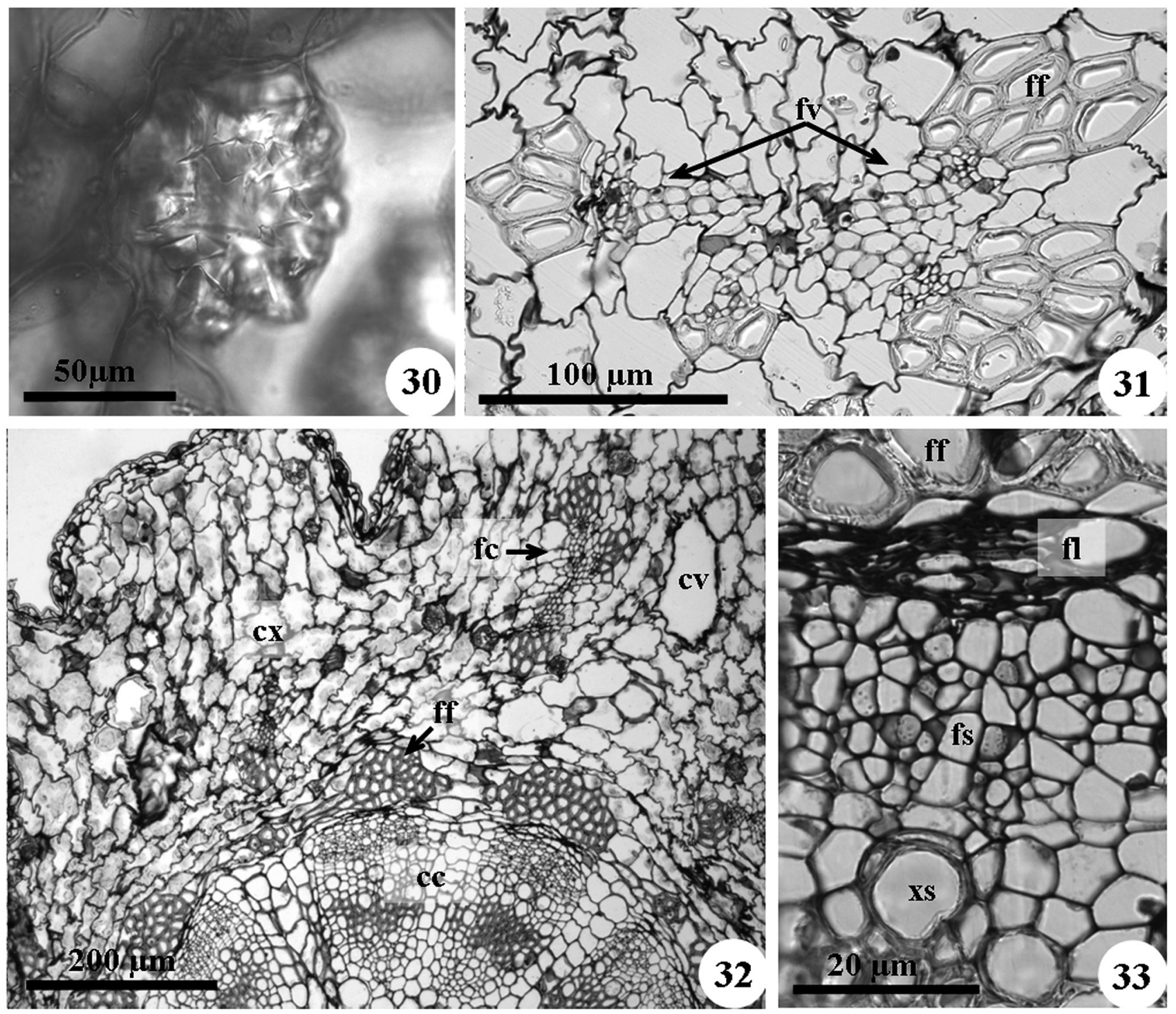

Figuras 30-33. Seções transversais do caule. 30. Detalhe de uma drusa de Lepismium warmingianum. 31-33. Rhipsalis cereuscula. 31. Detalhe dos feixes corticais. 32 . Aspecto geral do caule. 33 . Detalhe do floema. $\mathrm{cc}=$ cilindro central; $\mathrm{cv}=\mathrm{cavidade}$ mucilaginosa; $\mathrm{cx}=$ córtex; $\mathrm{fc}=$ feixes corticais; $\mathrm{ff}=$ fibras associadas ao floema; $\mathrm{fl}=$ floema primário colapsado; fs = floema secundário; fv = feixe vascular; $\mathrm{xs}=$ xilema secundário.

O cilindro central das espécies estudadas é concêntrico (figuras 32-36), com expressivas calotas de fibras no pólo floemático, menos expressivas em E. phyllanthus. Essas fibras têm origem no periciclo, como também ressaltado por Soffiatti \& Angyalossy (2007) para espécies terrestres de Cactaceae. Gibson \& Nobel (1986) consideram essas fibras originárias do floema primário, fato não suportado pela presente análise, pois o floema primário colapsado é facilmente visível entre as fibras e o floema secundário, conforme também observaram Soffiatti \& Angyalossy (2007) e demonstrado na figura 33.
O xilema das espécies analisadas possui grande proporção de fibras em relação aos elementos de vaso, como também observado por Mauseth \& Plemons-Rodriguez (1998) em representantes das tribos Hylocereeae e Rhipsalideae. Estes autores estimaram que, nessas tribos, aproximadamente $93 \%$ dos constituintes do xilema são representados por fibras, sendo esta a maior proporção entre as espécies da subfamília Cactoideae.

A faixa cambial é bastante visível em todas as espécies analisadas, estando constituída por 2-3 camadas de células achatadas. Os raios são formados 

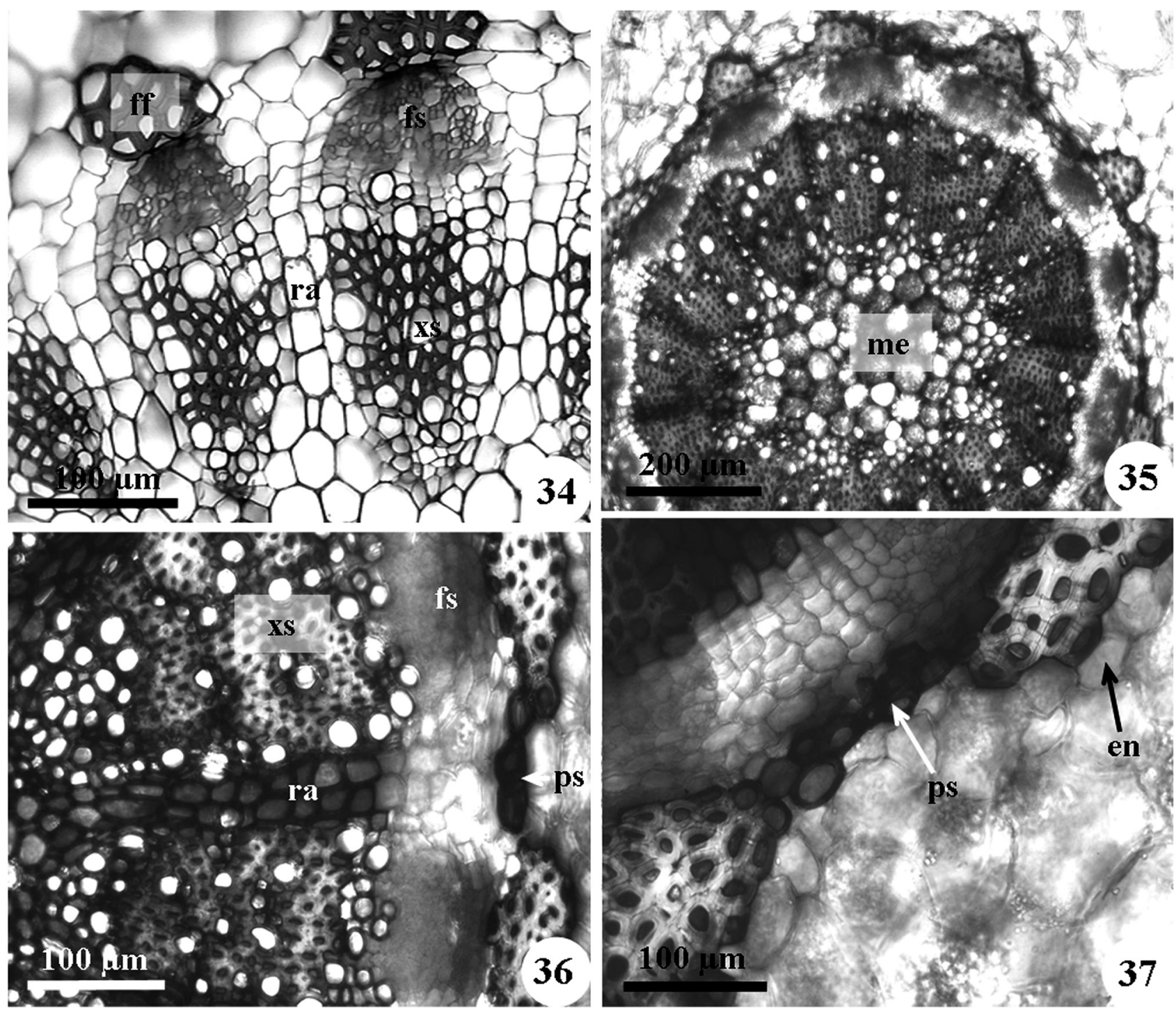

Figuras 34-37. Seções transversais do cilindro central. 34. Rhipsalis baccifera, caule jovem. 35. Lepismium warmingianum, caule maduro. 36. $R$. sulcata, caule maduro. 37. L. cruciforme, caule maduro. $\mathrm{cc}=$ cilindro central; $\mathrm{en}=$ endoderme; $\mathrm{ff}=$ fibras associadas ao floema; $\mathrm{fs}$ = floema secundário; me = medula ps = periciclo esclerificado, $\mathrm{ra}=$ raios; $\mathrm{xs}=$ xilema secundário.

por 1-3 camadas de células com lume volumoso (figuras 34, 36), com lignificação no xilema. O cilindro central encerra uma medula parenquimática (figura 35), com células alongadas axialmente, podendo ou não ter espessamento nas paredes celulares (tabela 1). Drusas ou cristais prismáticos são comuns nesta porção, assim como as células mucilaginosas nas porções não lignificadas.

Nas amostras analisadas de caules jovens, as células do periciclo não se mostram distintas das demais células corticais, mas tornam-se esclerificadas nas porções maduras (figuras 36-37).
Dentre as características observadas nas espécies analisadas, destacam-se: cutícula espessa e cera epicuticular, estômatos localizados em depressões da epiderme, presença de hipoderme colenquimática, grandes proporções de parênquima aqüífero e células mucilaginosas, como as mais expressivas, características de espécies de Cactaceae e relacionadas à ambientes xerofíticos. Embora as plantas epífitas sejam predominantes nas florestas tropicais, a presença destas características certamente favoreceu espécies de Cactaceae na ocupação do hábito epifítico, onde a escassez de água e nutrientes atua como fator limitante. 
Em adição, muitas características encontradas nas espécies estudadas revelam importante valor taxonômico, auxiliando na separação das espécies, como a estrutura cuticular, arranjo das células epidérmicas, caracteres dos complexos estomáticos, número de estratos e grau de espessamento da hipoderme, distribuição das células mucilaginosas, presença de cavidades mucilaginosas e idioblastos cristalíferos no córtex e espessamentos das células da região medular.

\section{Agradecimentos}

Agradecemos a contribuição do Prof. Dr. Fábio Amodeo Lânsac-Toha e do Biólogo Dr. Luiz Felipe Machado Velho (Nupélia/UEM), pela concessão de uso do fotomicroscópio.

\section{Literatura citada}

Barthlott, W. \& Hunt, D. 1993. Cactaceae. In: K. Kubitzki, J.G. Rohwer \& V. Bittrich (eds.). The families and genera of vascular plants. v. 2. Flowering plants. Dicotyledons: Magnoliid, Hamamelid and Caryophyllid families. Springer-Verlag, Berlin, pp. 161-197.

Benzing, D.H. 1990. Vascular epiphytes - general biology and related biota. Cambridge University Press, Cambridge.

Bukatsch, F. 1972. Bermerkungen zur Doppelfärbung Astrablau-Safranin. Mikrokosmos 61: 255.

Calvente, A.M., Andreata, R.H.P. \& Vieira, R.C. 2008. Stem anatomy of Rhipsalis (Cactaceae) and its relevance for taxonomy. Plant Systematic and Evolution. DOI: 10.1007/s00606-008-0052-9.

Darling, M.S. 1989. Epidermis and hypodermis of the saguaro cactus (Cereus giganteus): anatomy and spectral properties. American Journal of Botany 76: 1698-1706.

Dettke, G.A., Orfrini, A.C., Imoto, S.S. \& MilanezeGutierre, M.A. 2004. Anatomia do caule e raízes de Cryptocereus anthonyanus Alex. (Cactaceae). Arquivos da APADEC 8: 38-39.

Domínguez, E., Heredia, A., Serrano, J.M., Laguna, L., Reina, J.J. \& Casado, C.G. 1998. La cutícula vegetal: estructura y funciones. Ecologia 12: 293-305.

Eggli, U. 1984. Stomatal types of Cactaceae. Plant Systematics and Evolution 146: 197-214.

Franceschi, V.R. \& Horner Junior, H.T. 1980. Calcium oxalate crystals in plants. Botanical Review 46: 361-427.

Gerlach, D. 1984. Botanische Mikrotechnik. Georg Thieme Verlag, Stuttgart.

Gibson, A.C. \& Nobel, P.S. 1986. The cactus primer. Haward University Press, Cambridge.

Helbsing, S., Riederer, M. \& Zotz, G. 2000. Cuticles of vascular epiphytes: efficient barriers for water loss after stomatal closure? Annals of Botany 86: 765-769.

Johansen, D.A. 1940. Plant microtechnique. Mcgraw-Hill, New York.

Kraus, J. \& Arduin, M. 1997. Manual básico de método em morfologia vegetal. Editora Universidade Rural, Rio de Janeiro.

Loza-Cornejo, S. \& Terrazas, T. 2003. Epidermal and hypodermal characteristics in North American Cactoideae (Cactaceae). Journal of Plant Research 116: 27-35.

Mauseth, J.D. 1988. Plant anatomy. Benjamin/Cummings, Menlo Park.

Mauseth, J.D. 1995. Collapsible water-storage cells in cacti. Bulletin Torrey Botanical Club 122: 145-151.

Mauseth, J.D. \& Plemons-Rodriguez, B.J. 1998. Evolution of extreme xeromorphic characters in wood: a study of nine evolutionary lines in Cactaceae. American Journal of Botany 85: 209-218.

Metcalfe, C.R. \& Chalk, L. 1979. Cactaceae. In: C.R. Metcalfe \& L. Chalk. Anatomy of the dicotyledons. 1 ed. Clarendon Press, Oxford, pp. 698-705.

Morris, M.W., Stern, W.L. \& Judd, W.S. 1996. Vegetative anatomy and systematic of subtribe Dendrobiinae (Orchidaceae). Botanical Journal of the Linnaean Society 120: 89-114.

Nobel, P.S. 1978. Surface temperatures of cacti-influences of environmental and morphological factors. Ecology 59: 986-996.

Nyffeler, R. 2002. Phylogenetic relationship in the cactus family (Cactaceae) based on evidence from trnK/matK and $\operatorname{trn} L-\operatorname{trn} F$ sequences. American Journal of Botany 89: 312-326.

Nyffeler, R. \& Eggli, U. 1997. Comparative stem anatomy and systematics of Eriosyce sensu lato (Cactaceae). Annals of Botany 80: 767-786.

Paiva, E.A.S. \& Machado, S.R. 2005. Role of intermediary cells in Peltodon radicans (Lamiaceae) in the transfer of calcium and formation of calcium oxalate crystals. Brazilian Archives of Biology and Technology 48: 147-153.

Sass, J.E. 1951. Botanical microtechnique. 2 ed. The Iowa State College Press, Ames.

Scheinvar, L. 1985. Cactáceas. Flora Ilustrada Catarinense. Herbário Barbosa Rodrigues, Itajaí.

Soffiatti, P. \& Angyalossy, V. 2007. Anatomy of Brazilian Cereeae (subfamily Cactoideae, Cactaceae): Arrojadoa Britton \& Rose, Stephanocereus A. Berger and Brasilicereus Backeberg. Acta Botanica Brasilica 21: 813-822.

Terrazas, T. \& Arias, S. 2003. Comparative stem anatomy in the subfamily Cactoideae. Botanical Review 68: 444-473.

Terrazas, T. \& Mauseth, J.D. 2002. Stem anatomy and morphology. In: P.S. Nobel (ed.) The cacti: biology and uses. California University Press, Berkeley, pp.47-60. 